\title{
Citizen-Centric Strategies During Crisis Outbreak: An Overview
}

\author{
Siti Daleela Mohd Wahid \\ Fac. of Business Management, Universiti Teknologi MARA \\ 78000, Melaka, Malaysia. \\ E-mail: sitid365@uitm.edu.my
}

Siti Hajjar Mohd Amin

Fac. of Administrative Science \& Policy Studies, Universiti Teknologi MARA

40450 Selangor, Malaysia.

E-mail: hajjar@uitm.edu.my

\begin{abstract}
Abdul Jalil Mohamed Ali
Fac. of Administrative Science \& Policy Studies, Universiti Teknologi MARA

40450, Selangor, Malaysia

E-mail: ajali1838@uitm.edu.my
\end{abstract}

\begin{abstract}
Aida Abdullah
Fac. of Administrative Science \& Policy Studies, Universiti Teknologi MARA 40450, Selangor, Malaysia.

E-mail: aida547@uitm.edu.my
\end{abstract}

Siti Mariam Ali

Fac. of Business Management, Universiti Teknologi MARA 78000, Melaka, Malaysia.

E-mail: smali@uitm.edu.my 
Siti Noraziana Azis

Fac. of Business Management, Universiti Teknologi MARA 78000, Melaka, Malaysia.

E-mail: noraziana@uitm.edu.my

Received: Sep. 6, 2020 Accepted: Oct. 11, 2020 Online published: Nov. 1, 2020

doi:10.5296/jpag.v10i4.17646ＵRL: https://doi.org/10.5296/jpag.v10i4.17646

\begin{abstract}
Citizen-centric has been a major focus area for professionals, managers and scholars for nearly three decades because of its profound impact on policy making and service delivery. A massive number of studies on citizen-centric have been carried out by past scholars which resulted in a large volume of strategies but there has been little examination of these strategies in the crisis context. This study aims to produce a citizen-centric model that can be used during a crisis. There is a need to generalize the strategies that are capable of forming a universal citizen-centric model during crises. This study is an exploratory analysis of previous literatures in the context of public administration that has shed light by examining the indicators of citizen-centric concepts during crisis.
\end{abstract}

Keywords: citizen-centric strategies, public administration, crisis

\title{
1. Introduction
}

Due to its significant effect on policymaking and service delivery, citizen-centric has been a significant field of focus for practitioners, administrators, and researchers for almost three decades. There has been ongoing research on the definition, modelling, estimation, data collection process, data analysis, and citizen-centric problems leading to the researchers establishing a sound foundation. Researchers and public managers always improvise the components of the citizen-centric approach embedded in government strategies. This process is necessary to improve citizen satisfaction and increased trust. This model has gained importance as it does not only help in learning the factors associated with it but also will provide a direction for improvements of government strategies and citizen satisfaction.

In tandem with the strong starting points of citizen satisfaction with services, economic stability, health awareness and the rise of young populations, citizen expectations of government services have been on the rise. Recent OECD reports highlight that countries in the region need to strengthen public sector institutional capacities to improve citizens' quality of life and to foster inclusive and sustainable growth (OECD \& ADB, 2019). However, the recent political changes and with the Covid-19 outbreak, the federal government of Malaysia has entered a perfect storm of global and national economic challenges with serious socio-political implications. "Covid-19 represents the new government's first, biggest and 
most visible test of competence. Any failures, perceived or real, will further affect the perception of legitimacy of this government" (Bowie, 2020, March 16). As we can observe, the way our government responds to, manages, and communicates about crisis have direct implications on the public well-being and ultimately shape public opinion or expectation about local governments and government officials (Avery et al., 2016). For example, the new government had to make swift decisions to provide the Prihatin Rakyat Economic Stimulus Packages (PRIHATIN) to ease the burden of all Malaysians during the pandemic. The government also had to make a number of unpopular decisions in order to prevent the spread of Covid-19 such as the implementation of complete restriction of movement/assembly nationwide and closure of all government/private premises except those involved in essential services (Ministry of Finance Malaysia, 2020).

The present study is an attempt to review several articles reflecting on the citizen-centric approach in the context of crisis management. This overview is presented using a standard structure, i.e. covering brief discussion and the significant observations of the concepts. This documented knowledge from several research based article can be useful for researchers and practitioners in providing guidance on how to explore/modify current citizen-centric principles during normal times or crisis outbreaks.

\section{Literature Review}

\subsection{Definition of Citizen-Centric}

The citizen-centric approach is about shifting the government's attention onto service delivery from the citizens' eyes (people's interests come first) rather than the government's operational issues (Gupta, 2006). A high-quality service delivery relies on a thorough understanding of citizens' expectations, experiences, critical drivers of satisfaction, and a public decision-making framework that puts citizens at the center, making the government more citizen-centric (OECD, 2019).

\subsection{The Emergence of Citizen-Centric}

The rise of citizen-centric in public administration can be seen through the transition of Traditional Public Administration (TPA) (Fry \& Nigro, 1996) to New Public Governance (NPG) through New Public Management (NPM) (Hood, 2001), from passive citizen who received public goods then NPM enable people to have more choices in the delivery of public services respectively through privatization and commercialization of public sector. Meanwhile the New Public Governance (NPG) enables more collaborative processes among multiple interdependent actors including citizen (Robinson, 2015). All these transformation initiatives and strategies are intended to improve public service satisfaction. Therefore, a fresh understanding of the citizen-centric approach in the current government scenario is needed.

\subsection{Strategies of Citizen-Centric Approach During Crisis Outbreak}

The present study is an attempt to review articles in light of the citizen-centric approach in crisis context (CCC). This overview is presented using a standard structure (i.e. covering 
brief discussion and the significant observations on the concepts based on research-based articles). The brief discussions on the concepts are as follows:

a. CCC1. Who Do You Trust? Comparing People-Centered Communications in Disaster Situations in the United States and China

White and $\mathrm{Fu}$ (2012) used a theoretical sampling method to analyze and evaluate communications in two crisis: Sichuan earthquake in China and Hurricane Katrina in the United States. This study is moving away from a hierarchical communication model to a people-centered approach due to the surprising growth in various digital media types and the role that these media played in both natural disasters. In both the US and China disasters, citizens in crisis were exposed to multiple sources of information, ranging from media stories to interpersonal communications, to official announcements and speeches. People kept cross-checking with various sources to assess the reliability of the obtained information before making a decision. People in a crisis situation are more likely to believe in messages which are consistent across different outlets. White and $\mathrm{Fu}$ (2012) suggests the re-conceptualizing of the communication mechanism as an iterative, credibility-seeking model during a crisis using a vertical-first-horizontal-second (receiving information from the government or the media first and then obtaining confirmation from social media or interpersonal communications) or horizontal first- vertical-second (receiving information from family, friends, or neighbors in an interpersonal network or via social media first and then obtaining official confirmation from government/media). This model allows the principle of trust to be implemented as a variable. jIn In this sense, an authoritarian government like that in China can be seen as more successful in shortening the "credibility-seeking cycle'. In contrast, in the US, relatively high government mistrust levels can result in the need for more time and confirmation to ensure the reliability of the information. The situation in China reflected a high degree of national government confidence/trust, but a low level of local authorities' confidence compared to the US. Both countries demonstrated their abilities in crisis communication but each of them had strengths and weaknesses that can be a benchmark for more comprehensive policy agenda and implementation. In an emergency, questions regarding honesty and trust are of paramount importance, which directly affect media use or choice, regardless of the medium of dissemination. While the well-established media have a privileged role in crisis situations as sources of information, this status does not guarantee the dissemination of accurate information. Communication in crises is necessary, and any changes of communication modes in real-time should not be ignored by the government. It seems likely that any overall policy response to emergencies will need to integrate the current modes of communication. Taking into account the changes in the medium of communication favored by the people, the way of delivery and the frequency of communication with the people can be considered as citizen-centric in managing the crisis.

b. CCC2. Understanding Risk Communication Gaps through E-Government Website and Twitter Hashtag Content Analyses

Chatfield and Reddick (2015) examines disaster risk communications during the February 
2014 Mt. Sinabung eruptions in Indonesia, causing 16 deaths and 30,000 people evacuated. The authors critically looked at the one-way government-to-citizen communications via e-government websites and multi-directional communications from Twitter and people via the \#sinabung hashtag and exchange perceptions of a volcano risk regarding affected villagers. The review on the \#sinabung on Twitter found evidence of a lack of leadership and government involvement in communicating risk management and leadership in reacting to the Indonesian public's concerns about the Mt. Sinabung tragedy. Twitter can be used effectively by the government that would adopt citizen-centric e-governance as a multi-directional framework for the government communication of threats. It helps a lot in terms of sharing risk perceptions and information about disasters with the public quickly and efficiently. Referring to the context of the crisis, social media can be a significant platform to be used by the government because people are more comfortable using the platform to spread real-time events. This is in line with the definition proposed by Gupta (2006), citizen-centricity is about shifting the government's attention on service delivery from the citizens' eyes rather than the government's operational issues. The government needs to consider embedding the changes to make it possible for agencies to be more attentive to people's issues, particularly during a crisis.

CCC3. The Need for an Integrated Disaster Management System for Lead Responding Agency in Malaysia During Response and Recovery Phase

Khairilmizal et al. (2016) stresses abilities, capacity, and a sound system to effectively handle disaster during response and recovery phases. In response to his survey, 407 respondents who are responsible for making decisions during disasters were selected by the lead response agency in Malaysia, Fire and Rescue Department Malaysia (RFDM). Studies have shown that the response and recovery process of disaster management in Malaysia in particular needs to be assisted by a computerized framework to assist the lead response agency in Malaysia in handling disaster as it occurs. Conclusively, more than 80 percent of respondents agreed that experts are required during disaster response and recovery processes to assist responders in managing command structure, preparation and information processing, coordination, situation knowledge, and finally resources and logistics. This study demonstrates the significance of the leadership and support system role in providing successful citizen response and recovery process. This is in line with Chen et al. (2019) management support, as the finding suggests, is an important driver for all aspects of performance: effectiveness, efficiency, and accountability in cross-boundary system. Thus, Dais et al. (2012) highlight citizen-centric government needs to raise awareness in its internal sense for effective management of resources and skills, thus requiring the adoption of a whole new paradigm in terms of providing services to people. Through this process, all participating agencies would be able to collaborate cordially and effectively during a crisis.

CCC4. Government Trust, Social Trust, and Citizens' Risk Concerns: Evidence from Crisis Management in China

Trust among citizens in government is key to their perception of social risks. Ma and Christensen (2019) research explores the impact of institutional and social trust on citizens' 
perceptions of risk through observational data from 30 provincial capitals in China. Understanding the risk focuses on two factors: national emergencies (such as traffic accidents) and risks to public health (such as food safety). The result shows that social trust was found to vary across various levels of government. It is essential because trust can further influence perceptions of risk and contribute to undermining the willingness and ability of people to mitigate risks and support the capacity for risk management and governance in dealing with crisis. Kamaruddin and MdNoor (2017) also stress on citizens' active involvement as part of a citizen-centric approach. As reported by World Bank (2018), citizens are the main stakeholders in the citizen-centric delivery system; therefore, citizens' needs and voices are considered during the various stages of the design, delivery, and evaluation/review of public service.

CCC5. The New Ecology of Tornado Warning Information: A Natural Experiment Assessing Threat Intensity and Citizen-to-Citizen Information Sharing

In emergency management, information (such as warning messages) is communicated not only to the public from a source of authority but also among the public members. Robinson et al. (2019) used a series of storms in Oklahoma in 2016 as their case study. The authors analyzed how information on tornado warnings reached the public and who received and exchanged knowledge about the storm and determined the effect of gender and age in the process of sharing knowledge during an emergency. It shows that exposure to an emergency facilitates the exchange of information across various media and technology. The tornado effect erases the gender difference in exchanging knowledge, while it has little impact on the media outlets that are most common among older respondents.

Nevertheless, emergency managers need to carefully disseminate information, as some outlets encourage the distribution of information among people but do not appear to reach vulnerable communities, especially the elderly. This study is consistent with the citizen-centric principles outlined by Cai and Wang (2006). It consists of developing public services to meet people's needs, the openness of information for easy access, and quality in service delivery. According to Song et al. (2020), there could be a similar degree of public services for citizens from different socioeconomic classes. However, they can come to different conclusions about the services, since different sets of perceived success and expectations affect their perceptions. Even a successful alert plan aimed at reaching the public needs to align efforts across a variety of techniques tailored to the community's demographics.

CCC6. Hiding in Plain Sight: Conceptualizing the Creeping Crisis

The COVID-19 crisis is a clear warning to the vulnerability of contemporary society: the spreading crisis. It carries a potential threat for social disruption but that potential is not entirely grasped and understood. An accumulation of these creeping crises will erode public institutional faith. Boin et al. (2020) suggest a concept of a creeping crisis. Here, a creeping crisis is a threat to widely shared societal values or life. It is foreshadowed by precursor events, subject to varying degrees of political and/or societal attention while the creeping crisis is impartially or insufficiently addressed by authorities. The escalating crisis offers an 
invaluable asset for authorities: time to act. Thus, for it to be brought under control, the rising crisis would need sustained attention from authorities. The authors formulated questions on speed and attention convergence and the prospects for handling this emerging crisis. Early intervention also carries risks: if draconic steps are placed in place when the crisis's effect is still unclear, the public can quickly lose faith in the issuing government. These perspectives leave a range of choices for policymakers from which it may be challenging to select. Besides timing, the biggest challenge may well be the design of the response. After all, the mere notion of a creeping crisis has real consequences on accountability: apparently there was a sustained time period during which remedial action was possible. If the emerging crisis occurs, then-incumbent leaders will lose. If it is not put under control, then the system will fail. A creeping crisis has the potential to reveal governance vulnerabilities. The shortcomings of existing crisis management systems are laid bare, for example, pandemic outbreak, climate change, cyber-attacks, and misinformation campaigns. These scenarios might contribute to a long-debated topic of citizen frustration with public services which has been continuously highlighted in government transformational initiatives (Van de Walle, 2017) and at the end, the power and right to rule will be lost (Mok, 2020). According to the Organisation for Economic Cooperation and Development \& Asian Development Bank (OECD \& ADB, 2019), a government is capable of achieving a citizen-centric approach to policymaking and service delivery through collaboration between departments.

CCC7. Responsibilization in Contemporary Swedish Crisis Management: Expanding 'Bare Life' Biopolitics through Exceptionalism and Neoliberal Governmentality

Rådestad and Larsson (2020) aim to investigate the changing relations between individuals and public authorities within the Swedish crisis management system from 1995 to 2017. The authors observed that Sweden had embraced a broader security view that focuses on domestic security and critical infrastructure defense, using alternative governance strategies. This scenario contributed to the development of collaborative arrangements involving public and private actors and the extensive responsibilization to individuals. This study has revealed that amid a general discourse that encourages cooperation involving NGOs, volunteers, and individuals in Swedish crisis management, such involvement is limited to supporting roles designed to unburden public authorities during a crisis. Individuals are assumed to be helpless objects when research indicates that they have a capacity for positive contributions in times of crisis. In this regard, this article can serve as a critical note since it illustrates the continuity of exceptionalism, emergency, and fear politics that direct contemporary crisis management policies. This scenario may also be an obstacle to the government's implementation of a comprehensive citizen-centered policy. The idea of citizen-centric maintains that citizen is at the centre of design approach of public service delivery (Malhotra, 2015) and strategic planning (Kopackova, 2019), not only emphasize on the product nor its technology.

CCC8. "What is a Sociologist Doing Here?” An Unconventional People-Centered Approach to Improve Warning Implementation in the Sendai Framework for Disaster Risk Reduction

Marchezini (2020) uses institutional ethnography to analyze the 2012-2018 implementation of Brazil's national warning system. The Sendai Framework for Disaster Risk Reduction 
2015-2030 proposes multiple actions for early warning systems (EWSs). However, there are weaknesses in their implementing methods. The problems associated with everyday activities and the interdisciplinary work on multi-hazard and people-centric approaches are explored in the four axes of EWSs. Based on observation, Marchezini (2020) proposes several crucial steps, especially on social and political aspects, such as improving data and information access for different sectors, and engaging different audiences in early warning systems (EWS) as an innovative people-centered approach of Sendai Mechanism for Disaster Risk Reduction. In order to determine the activities suitability, particularly in complex and dynamic environments, effective contact with the community is required. Malchenko and Smirnova (2019) developed bottom-up citizen-centered urban services typology, focusing on digital natives as the critical users of smart city solutions as guidance for future researchers and smart city managers to better categorize technology and human-driven approaches. This typology may also be a useful guidance for crisis management. Nevertheless, the main important element is still in the good governance where the government requires to have an effective communication method with different categories of public. In addition, the element of transparency and information accessibility are also very crucial at this stage as people are often panicking and helpless during crisis outbreak.

\section{The Formation of Citizen-Centric Strategies During Crisis}

By bridging the gap in the literature and aligning with the current government strategies, we form a citizen-centric strategy in the context of a crisis. The way our government reacts to, addresses, and interacts on a crisis has clear consequences for public well-being. There is no doubt that these responses influence public sentiment or attitudes regarding local governments and elected officials (Avery et al., 2016). As Jakobsen et al. (2016) stated that beyond paying taxes and voting, citizens play several vital roles in public administration. Citizens take part in the design, production, and delivery of the public services they receive. Thus, citizens are subjected to the rules imposed by the state, and the ultimate evaluators of administrative outputs. Citizens today expect public sector programs to be more open, accessible, and sensitive (Dudley et al., 2015, July 1). Therefore, many administrative reform initiatives have explicitly made a connection between the need to reform public services, improving citizen satisfaction with public services and maintaining or restoring the public trust in government (Van de Walle, 2017). According to the OECD and ADB (2019), government is able to achieve citizen-centric approach for policymaking and service delivery through coordination between agencies and make use of user preference data, being transparent and allowing for more active involvement among stakeholders and producing right policy and expenditure choices towards responding to the citizens' needs. We also believe that this concept heightens citizen-centric strategies and simultaneously improve the quality of life, attitude, engagement, self-efficacy, and need. Following the suggestion, we form a citizen-centric strategy during crisis outbreak, as presented in Figure 2.1. 


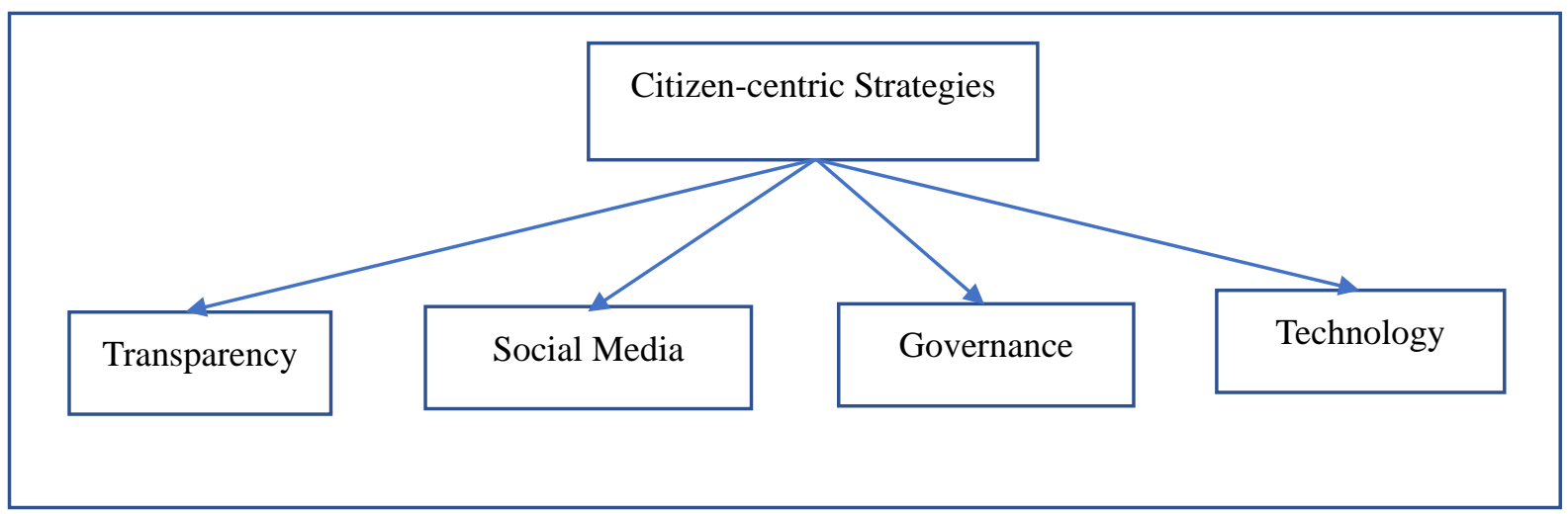

Figure 2.1. Conceptual model of citizen-centric strategies during crisis

Sources: Kumar (2019), Kamaruddin and MdNoor (2017) and Naswir et al. (2019)

a. Transparency

Transparency is a noticeable feature of crisis outbreak as the government demands that knowledge be continuously communicated and exchanged to prevent people from panicking with an uncertain situation. Public administrations must exchange knowledge and tell their stories, as stated in World Bank (2018) so that people can better understand the challenges of the public sector. This process is in line with research performed by Jordan et al. (2017) shows that access and appearance are the two most essential components of transparency in popular financial report (PFR) context. Thus, the citizen-centric report calls for a more user-friendly report that is more understandable by the public as it discloses more information in a short and straightforward summary. Thus, in the crisis context, communication is the key. We suggest better communication mechanisms should be set up and more transparency about public resources, priority action areas and outcomes. Consistent with our recommendation, White and $\mathrm{Fu}$ (2012) postulated that the communication mechanism needs to re-conceptualized as an iterative, credibility-seeking model. This model categorizes crisis communication into two way vertical-first-horizontal-second (receiving information from the government or the media first and then obtaining confirmation from social media or interpersonal communications) or horizontal first- vertical-second (receiving information from family, friends, or neighbours in an interpersonal network or via social media first and then obtaining official confirmation from government/media).

Communication use in emergencies is crucial, and the government cannot overlook changes in communication types in real time. It seems likely that any overall policy response to emergencies will need to integrate the current modes of communication. Considering the changes in the medium of communication favored by the people, the way of delivery and the frequency of communication with the people can be considered as citizen-centric in managing the crisis.

\section{b. Social media}

In an emergency, questions regarding honesty and trust are of paramount importance, which directly affects media use or choice, regardless of the medium of dissemination. While the 
well-established media have a privileged role in crises as sources of information, this status does not guarantee information accuracy. Alternatively, social media can be a powerful platform to be considered and used by the government because the people like to use the platform to spread real-time events. Based on the concept of psychological distance, results from Porumbescu (2016) indicate less detailed information in social media may be more effective in improving ties between people and their government compared to detailed information from websites of e-government. Thus, this study confirms the use of public sector social media accounts is positively related to satisfaction and perceptions of public sector trustworthiness.

Nevertheless, research conducted by Reddick et al. (2017) found that social media used mainly for "one-way" communication with government to educate citizen, with little meaningful changes in policy. For a more positive outcome and significant e-participation process, the author urged the public sector to incorporate social media correctly. Here, Aschhoff (2018) demonstrates that social media appears to be a cost-effective medium for direct interaction with all people. However, public organizations need to use more advanced communication tools and critical training for a better collaborative process between the organizations and citizen.

\section{c. Governance}

We demonstrate the significant role of the leadership and support system in providing successful citizen response and recovery during the crisis process. This aspect is in line with Southeast Asia's central objective in fostering a citizen-centric approach, as member countries need to improve public sector institutions' capacity to promote well-being and inclusive and sustainable development (ASEAN, 2015). Citizen-centric indicators also partly essential for evaluating the quality of efficient and equal governance systems (OECD \& ADB, 2019). Therefore, government require to adopt a new strategy in providing citizen-centric services through effective management resources and skills (Dais et al., 2012). This strategic management enables various government agencies to collaborate cordially and effectively during a crisis. Citizen-centric model of governmental entrepreneurship developed by Kumar (2019) does highlight the importance of public sector governance for better social program outcomes at the same time-solving issues of bureaucratic hurdles and leverage the untapped capabilities of the marginalized citizen. Chatfield and Reddick (2015) found that social media (in this case, Twitter) can be a governance platform between public agencies and act as a multi-directional risk communication tool to quickly and effectively share risk perceptions and disaster information with the public. Thus, it is crucially important to have management support from leaders, shared goals, and inter-organizational trust in performing cross-boundary government system (Chen et al., 2019).

\section{d. Technology}

Technology is an essential function in promoting modes of communication and information sharing during the crisis outbreak. It also allows for collaborative mechanisms and helps response agency to become more effective in crisis management. Heeks (2003) warns that e-government is not merely computerization of government systems, but a belief in the ability 
of technology to achieve high levels of improvement in various areas of citizen service delivery. Recently, data-driven in the government system can become as part of reformation initiatives for better governance and improves public service delivery by utilizing big data (Agbozo et al., 2018). Here, a unique service delivery based on the individual needs more inclusive and responsive government (Misra et al., 2018). It is proven from action design research applied by Giesbrecht et al. (2016), the usage of technology was able to help public sector front office change from providing government-centric, transaction-oriented processing services to offering high level and citizen-centric services.

\section{Discussion of the Study}

Governments need to improve their internal collaboration through departments in order to facilitate a citizen-centric agenda in the event of a crisis. Citizen-centric and creative organizational culture increases productivity and accountability, while administrative interdependence affects effectiveness and accountability (Chen et al., 2019). Meanwhile, transparency is a noticeable feature of crisis outbreak as the government demands that knowledge to be continuously communicated and exchanged to prevent people from panicking with an uncertain situation. Public administration must exchange knowledge and tell their stories, as stated in World Bank (2018), so that people can better understand the challenges of the public sector. There is also considerable space for more efficient communication mechanisms to be set up and be more transparent about public resources, priority action areas and outcomes. To achieve a citizen-centric agenda, the government needs to be transparent and respond to the needs of citizen for inclusive policy making (OECD \& ADB, 2019). Consequently, with enhanced transparency and proactivity, a state institution can improve its image with citizens and might even benefit from citizen initiatives. Besides, these efforts are strategically aligned which support an increasing role of information and communication technologies promoted by Sustainable Development Goals (SDG) (Das \& Mishra, 2018).

Most crisis article discussed above are describing technology's essential function in promoting modes of communication and knowledge sharing. It also allows for multi-stakeholder collaborative mechanisms and helps response agency to become more effective and productive in crisis management. Data-driven in the government system can become part of reformation initiatives for better governance and improved public service delivery (Agbozo et al., 2018). Here, a superior service delivery based on individuals needs more inclusive and responsive government (Misra et al., 2018).

Another possible component that can be utilized in times of crisis is by encouraging active participation among the people. This extra support may help reduce the burden of public authorities or the frontline in times of crisis. Active participation is in line with the New Public Governance (NPG) which promotes more collaborative processes among multiple interdependent actors to encourage inclusive policymaking (Robinson, 2015). However, there are a handful of questions raised on real and perceived challenges in embracing citizen engagement (Brandsen et al., 2018). 


\section{Contributions of the Study}

\section{a. To the public managers}

This research can be helpful in cognitive and behavioural public management during a pandemic crisis. The way government reacts to, manages, and deals with the crisis has direct repercussions for public well-being. This study recommends that for a successful implementation of crisis management, the response agencies need to cooperate in handling crisis management. The public manager requires to plan and monitor the process and frequency of communication with citizen at the same time acknowledging citizen preferred form of communication in order to claim as citizen-centric government in managing crisis outbreak.

\section{b. To the policymakers}

This conceptual study gives clear, practical evidence that the nature of overall crisis management itself; therefore, crisis preparation should be adaptive and continuous. The government needs to strengthen open government initiatives and transparency policies. By doing so, it helps improve citizen knowledge and expectations on various public service delivery and processes by making more information accessible to citizen.

\section{Conclusion}

Integrating perspectives from the past literature and current empirical evidence in the area of citizen-centric approach, we propose that technology, governance, responsiveness and transparency will be capable of creating citizen-centric strategies with the public service during the pandemic crisis. Past scholars have pointed out that these attributes, including the quality of service, perceived efficiency, expectation, and confidence, are the "must-have" elements in citizen-centric concepts in normal times and during a pandemic crisis.

We strive to provide a parsimonious rather than a detailed model of citizen-centric strategies during crisis given that this field is still in its infancy. We acknowledge that the method chosen has its limitations. Firstly, this paper incorporates pieces of insights from reviewed articles with an insight into crisis management and citizen. It provides a conceptual idea of only one part - in a citizen-centric approach- of crisis management. It takes additional philosophical and analytical study to develop an understanding of the entire process.

Second, it is essential to remember that the variables chosen are by no means comprehensive in describing satisfaction with the citizen-centric public service. Nevertheless, we speculate that they are vital in shedding light on gaps in a citizen-centric approach that may exist in the background of the Malaysian government and evolve in other countries fighting a pandemic.

\section{Future Direction}

This paper is one of the first moves towards citizen-centric strategies in crisis management and points to many interesting topics and potential for empirical study. We have identified many important factors that need to be integrated into the model. However, the relationship between government decision-making in tackling the pandemic outbreak and citizen 
satisfaction is not widely known. How the government finds and uses information before, during, and after the crisis is not well understood. We believe that understanding this mechanism will provide us with fresh and vivid insights into overall management. For example, do they display an above-normal level of alertness to crisis? And what is the important contextual knowledge for finding and leveraging the crisis? Or to what extent does the government rely on "gut instincts" to determine the crisis scenario and the satisfaction of the people?

\section{Acknowledgments}

We would like to extend our gratitude to UiTM Melaka for funding this research under TEJA Grant UiTM Melaka (Ref No. GDT2020-29). Additionally, thank you to all team members for the effort, time and courage to complete the paper.

\section{References}

Agbozo, E., Alhassan, D., \& Spassov, K. (2018). Personal Data and Privacy Barriers to E-Government Adoption, Implementation and Development in Sub-Saharan Africa. International Conference on Electronic Governance and Open Society: Challenges in Eurasia,

Aschhoff, N. (2018). Citizens differ from organizations: Modeling a specific citizen-centered collaborative capacity. International Journal of Public Administration, 41(4), 284-296. https://doi.org/10.1080/01900692.2016.1263657

ASEAN. (2015). ASEAN Community Vision 2025 Report.
https://www.asean.org/wp-content/uploads/images/2015/November/aec-page/ASEAN-Comm unity-Vision-2025.pdf

Avery, E. J., Graham, M., \& Park, S. (2016). Planning makes (closer to) perfect: exploring United States' local government officials' evaluations of crisis management. Journal of $\begin{array}{llll}\text { contingencies } \quad \text { Crisis } & \text { Management, } & \text { 24(2), }\end{array}$ https://doi.org/10.1111/1468-5973.12109

Boin, A., Ekengren, M., \& Rhinard, M. (2020). Hiding in Plain Sight: Conceptualizing the Creeping Crisis. Risk, Hazards \& Crisis in Public Policy. https://doi.org/10.1002/rhc3.12193

Bowie, N. (2020, March 16). Malaysia loses its grip on Covid-19 outbreak. Asiatimes. Retrieved from https://asiatimes.com/2020/03/malaysia-loses-its-grip-on-covid-19-outbreak/

Brandsen, T., Steen, T., \& Verschuere, B. (2018). Co-production and co-creation: Engaging citizens in public services. Taylor \& Francis.

Cai, H., \& Wang, K. (2006). Service oriented design method and practice for constructing citizen-centric public services. 2006 IEEE International Conference on e-Business Engineering (ICEBE'06) (pp. 536-540), Shanghai, China.

Chatfield, A. T., \& Reddick, C. G. (2015). Understanding Risk Communication Gaps through E-Government Website and Twitter Hashtag Content Analyses: The Case of Indonesia's Mt. Sinabung Eruption. Journal of Homeland Security and Emergency Management, 12(2), 
351-385. https://doi.org/10.1515/jhsem-2014-0086

Chen, Y.-C., Hu, L.-T., Tseng, K.-C., Juang, W.-J., \& Chang, C.-K. (2019). Cross-boundary e-government systems: Determinants of performance. Government Information Quarterly, $36(3), 449-459$.

Dais, A., Nikolaidou, M., \& Anagnostopoulos, D. (2012). A web 2.0 citizen-centric model for t-government services. IEEE intelligent systems, 28(5), 10-18.

Das, R. K., \& Mishra, H. (2018). Smart E-Governance and Sustainable Development: Strategic Alignment Assessment Framework. Proceedings of the 11th International Conference on Theory and Practice of Electronic Governance (pp.690-692), Galway, Ireland: National University of Ireland Galway.

Dudley, E., Lin, D.-Y., Mancini, M., \& Ng, J. (2015, July 1). Implementing a citizen-centric approach to delivering government services. McKinsey \& Company. https://www.mckinsey.com/industries/public-and-social-sector/our-insights/implementing-a-c itizen-centric-approach-to-delivering-government-services\#

Fry, B. R., \& Nigro, L. G. (1996). Max Weber and US public administration: the administrator as neutral servant. Journal of Management History, 2(1), 37-46. https://doi.org/10.1108/13552529610105654

Giesbrecht, T., Scholl, H. J., \& Schwabe, G. (2016). Smart advisors in the front office: Designing employee-empowering and citizen-centric services. Government Information Quarterly, 33(4), 669-684. https://doi.org/10.1016/j.giq.2016.05.005

Gupta, D. N. (2006). Citizen-centric Approach for e-Governance. Computer Society India. https://www.csi-sigegov.org/1/5_392.pdf

Heeks, R. (2003). Most eGovernment-for-development projects fail: how can risks be reduced?

Hood, C. (2001). New public management. International encyclopedia of the social and behavioral sciences, 12553-12555.

Jakobsen, M., James, O., Moynihan, D., \& Nabatchi, T. (2016). JPART Virtual Issue on Citizen-State Interactions in Public Administration Research. Journal of Public Administration Research and Theory, 29(4), e8-e15. https://doi.org/10.1093/jopart/muw031

Jordan, M. M., Yusuf, J.-E., Berman, M., \& Gilchrist, C. (2017). Popular financial reports as fiscal transparency mechanisms: An assessment using the fiscal transparency index for the Citizen User. International Journal of Public Administration, 40(8), 625-636. https://doi.org/10.1080/01900692.2016.1186175

Kamaruddin, K. A., \& MdNoor, N. (2017). Citizen-centric demand model for transformational government systems (pp.139). Pacific Asia Conference on Information Systems (PACIS), Langkawi, Malaysia.

Khairilmizal, S., Hussin, M., Husna, A. K., Yassin, A. I. M., bin Wan, W. A. S. H., Hamid, A., 
Jusoh, M. H., ... Saadun, J. (2016). The need for an integrated disaster management system for lead responding agency in Malaysia during response and recovery phase. International Information Institute (Tokyo). Information, 19(8A), 3307.

Kopackova, H. (2019). Reflexion of citizens' needs in city strategies: The case study of selected cities of Visegrad group countries [Article]. Cities, 84, 159-171. https://doi.org/10.1016/j.cities.2018.08.004

Kumar, A. (2019). Citizen-centric model of governmental entrepreneurship Transforming public service management for the empowerment of marginalized women. Transforming Government- People Process and Policy, 13(1), 62-75. https://doi.org/10.1108/tg-03-2018-0023

Ma, L., \& Christensen, T. (2019). Government trust, social trust, and citizens' risk concerns: Evidence from crisis management in China. Public Performance \& Management Review, 42(2), 383-404. https://doi.org/10.1080/15309576.2018.1464478

Malchenko, Y. A., \& Smirnova, M. M. (2019). What drives consumers smart? the challenge of adoption of smart city solutions. https://doi.org/10.21638/spbu18.2019.305

Malhotra, C. (2015). A Design Framework for Evolving a Citizen-Centric Information Society. In Handbook of Research on Cultural and Economic Impacts of the Information Society (pp. 25-41). IGI Global.

Marchezini, V. (2020). "What is a sociologist doing here?" An unconventional people-centered approach to improve warning implementation in the Sendai framework for disaster risk reduction. International Journal of Disaster Risk Science, 1-12. https://doi.org/10.1007/s13753-020-00262-1

Ministry of Finance Malaysia. (2020). Perlaksanaan Pakej PRIHATIN Rakyat. https://pre2020.treasury.gov.my/flipbook/laksana1/

Misra, A., Misra, D. P., Mahapatra, S. S., \& Biswas, S. (2018). Digital transformation model: analytic approach on participatory governance \& community engagement in India (pp. 1-7). 19th Annual International Conference on Digital Government Research: Governance in the Data Age, The Netherlands: Delft University of Technology.

Mok, J. Y. (2020). Proposed non-linear relation between satisfaction with government performance and co-production: an initial empirical test. Public Management Review, 22(3), 432-451. https://doi.org/10.1080/14719037.2019.1599060

Naswir, R. Y., Maarop, N., Hasan, M., Daud, S., Samy, G. N., \& Magalingam, P. (2019). Towards a Conceptual Model to Evaluate Usability of Digital Government Services in Malaysia. higher education, 10(4).

OECD, \& ADB. (2019). Government at a Glance Southeast Asia 2019. OECD Publishing. https://doi.org/https://doi.org/10.1787/9789264305915-en

Porumbescu, G. A. (2016). Linking public sector social media and e-government website use 
to trust in government. Government Information Quarterly, 33(2), 291-304.

Rådestad, C., \& Larsson, O. (2020). Responsibilization in contemporary Swedish crisis management: expanding 'bare life'biopolitics through exceptionalism and neoliberal $\begin{array}{lllll}\text { governmentality. } & \text { Critical } & \text { Policy } & \text { Studies, } & \text { 14(1), }\end{array}$ https://doi.org/10.1080/19460171.2018.1530604

Reddick, C. G., Chatfield, A. T., \& Ojo, A. (2017). A social media text analytics framework for double-loop learning for citizen-centric public services: A case study of a local government Facebook use. Government Information Quarterly, 34(1), 110-125. https://doi.org/10.1016/j.giq.2016.11.001

Robinson, M. (2015). From old public administration to the new public service: Implications for public sector reform in developing countries. https://www.undp.org/content/dam/undp/library/capacity-development/

Robinson, S. E., Pudlo, J. M., \& Wehde, W. (2019). The New Ecology of Tornado Warning Information: A Natural Experiment Assessing Threat Intensity and Citizen-to-Citizen Information Sharing. Public Administration Review, 79(6), 905-916. https://doi.org/10.1111/puar.13030

Song, M., Kim, M., \& Favero, N. (2020). Social Class, Ingroup-Outgroup Comparison, and Citizen Evaluations: Is User Satisfaction Linked to Outcome Disparities? The American Review of Public Administration, 50(2), 205-218. https://doi.org/10.1177/0275074019874445

Van de Walle, S. (2017). Explaining Citizen Satisfaction and Dissatisfaction with Public Services. In (pp. 227-241). https://doi.org/10.1057/978-1-137-55269-3_11

White, J. D., \& Fu, K.-W. (2012). Who do you trust? Comparing people-centered communications in disaster situations in the United States and China. Journal of Comparative Policy Analysis: Research and Practice, 14(2), 126-142.

World Bank. (2018). Indicators of Citizen-Centric Public Service Delivery. W. B. Publications. https://elibrary.worldbank.org/doi/abs/10.1596/30030

\section{Copyright Disclaimer}

Copyright for this article is retained by the author(s), with first publication rights granted to the journal.

This is an open-access article distributed under the terms and conditions of the Creative Commons Attribution license (http://creativecommons.org/licenses/by/4.0/). 